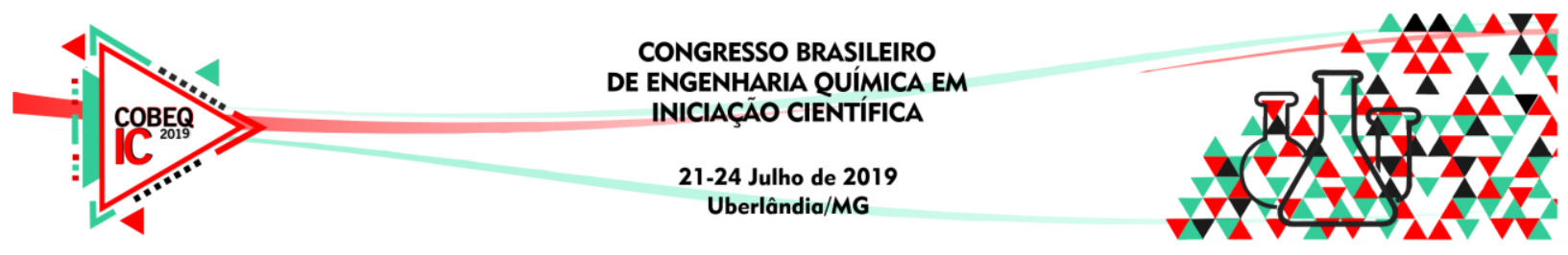

\title{
COMPOSTOS FENÓLICOS E CAPACIDADE ANTIOXIDANTE DE RESÍDUOS DE FRUTA
}

\author{
H. A. C. NERE ${ }^{1}$, W. R. CHIMATTI ${ }^{2}$, L. O. RIBEIRO ${ }^{3}$, C. N. KUNIGAMI ${ }^{3}$, C. S. S. \\ PEREIRA $^{1,2}$ \\ ${ }^{1}$ Universidade de Vassouras, Curso de Engenharia Química \\ ${ }^{2}$ Universidade de Vassouras, Mestrado em Ciências Ambientais \\ ${ }^{3}$ Instituto Nacional de Tecnologia, Laboratório de Análise Orgânica Instrumental \\ E-mail para contato: nady_nere@ hotmail.com
}

\begin{abstract}
RESUMO - Uma vez que os consumidores estão cada vez mais preocupados com a saúde, observa-se uma crescente demanda por frutas devido ao seu valor nutricional, por conter teores elevados de fibras, vitaminas $\mathrm{C}$ e outros compostos bioativos. Assim, o aproveitamento agroindustrial dos resíduos de frutas vem sendo bastante estimulado para elaboração de novos produtos. Deste modo, o objetivo deste estudo foi avaliar a capacidade antioxidante e o teor de compostos fenólicos totais de resíduos de laranja e de mamão provenientes da sua industrialização. O teor de compostos fenólicos foi obtido por meio da reação do reagente de Folin Ciocalteau com o extrato em meio básico e a capacidade antioxidante mensurada pela reação do extrato dos resíduos com o radical livre ABTS+•. Os resultados mostraram que o teor de compostos fenólicos do resíduo de laranja foi maior quando comparado com o resíduo de mamão $(\mathrm{p}<0,05)$. Como esperado, o resíduo de laranja apresentou maior capacidade antioxidante entre os resíduos avaliados, corroborando a correlação positiva entre o teor de compostos fenólicos e a capacidade antioxidante de matérias-primas vegetais. Portanto, este estudo mostra que estes resíduos agroindustriais podem ser utilizados pela a indústria alimentícia ou cosmética como ingrediente e/ou matéria-prima para obtenção de produtos de maior valor agregado.
\end{abstract}

\section{INTRODUÇÃO}

Em busca de uma vida mais saudável, a população tem buscado alimentos nutritivos e com características funcionais, o que refletiu no aumento do consumo de frutas e hortaliças visto que, evidencias epidemiológicas tem mostrado que o consumo frequente desses alimentos está relacionado com a redução da mortalidade e morbidade por doenças crônicas e degenerativas (Roesler et al, 2007). As frutas, por serem fontes de vitaminas, fibras e minerais, são alimentos nutricionalmente importantes na dieta (Melo et al, 2008).

Atribuídas à existência de substâncias bioativas que, mesmo em pequenas quantidades, apresentam efeitos fisiológicos, o consumo de frutas pode contribuir para a prevenção ou diminuição dos danos oxidativos causados por espécies de oxigênio reativo (Couto e Canniatti-Brazaca, 2010). 


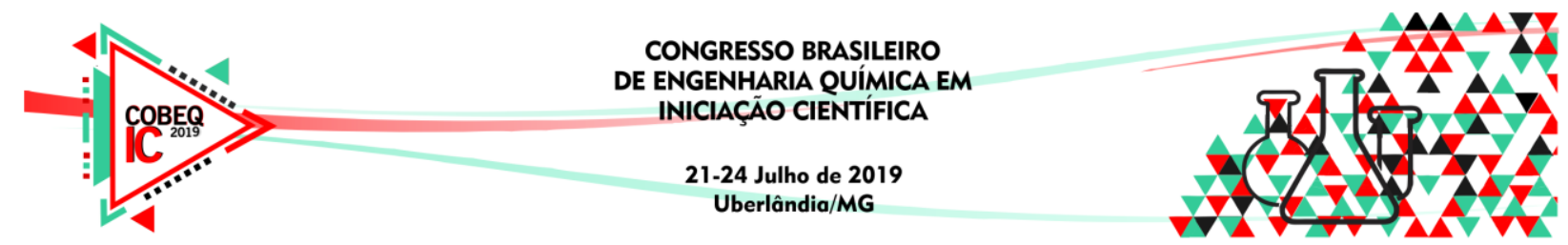

Desta forma, o aproveitamento agroindustrial de resíduos de frutas vem sendo bastante estimulado para elaboração de novos produtos, sendo uma forma de diminuir o desperdício, usando partes não convencionais, além de contribuir para a redução dos gastos com alimentação, já que esses também ajudam para o enriquecimento nutricional dos produtos (Cristo et al, 2015).

Aos compostos fenólicos, amplamente distribuídos no reino vegetal, principalmente nas frutas, estão relacionadas às ações biológicas como a capacidade antioxidante e ação antiinflamatória, podendo também apresentar ação vaso-protetora, reduzindo o risco do desenvolvimento de doenças cardiovasculares (Rocha et al, 2011).

Portanto, este trabalho teve como objetivo avaliar o teor de compostos fenólicos totais e a capacidade antioxidante dos resíduos do processamento de laranja e mamão, oriundos da produção de frutas cristalizadas.

\section{MATERIAL E MÉTODOS}

\subsection{Matéria-prima}

Para a realização deste trabalho foram utilizados resíduos de laranja e mamão disponibilizados por uma empresa do ramo alimentício, localizada na cidade de Três Rios/RJ, a qual produz frutas cristalizadas. Anualmente, são geradas aproximadamente cinco toneladas de resíduos de frutas. As amostras dos resíduos foram acondicionas em recipientes apropriados, e encaminhadas sob refrigeração ao laboratório de Engenharia Química da Universidade de Vassouras, onde foram armazenados a $10^{\circ} \mathrm{C}$ até o momento das análises.

Os resíduos de laranja e mamão foram sanitizados, utilizando uma solução de hipoclorito de sódio $(1 \mathrm{ppm})$. Após a sanitização, o resíduo foi submetido à secagem em estufa com circulação de ar (QUIMIS, $n^{\circ} 089$ ) a $60{ }^{\circ} \mathrm{C}$.

Depois de seco, os resíduos foram moídos em liquidificador doméstico até obtenção de uma farinha homogênea. O fluxograma do processo de obtenção da farinha é apresentado na Figura 1.

Figura 1- Fluxograma de elaboração das farinhas das frutas
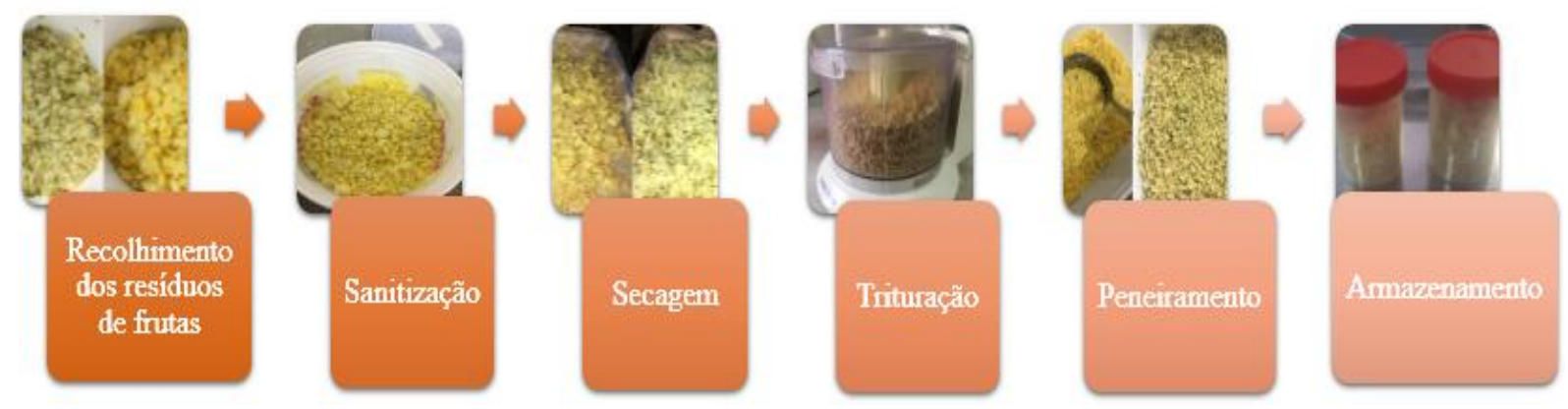

Cerca de 15 g de cada farinha dos resíduos, laranja e mamão, foram enviadas ao Laboratório de Análise Orgânica Instrumental (LANOI) do Instituto Nacional de Tecnologia 


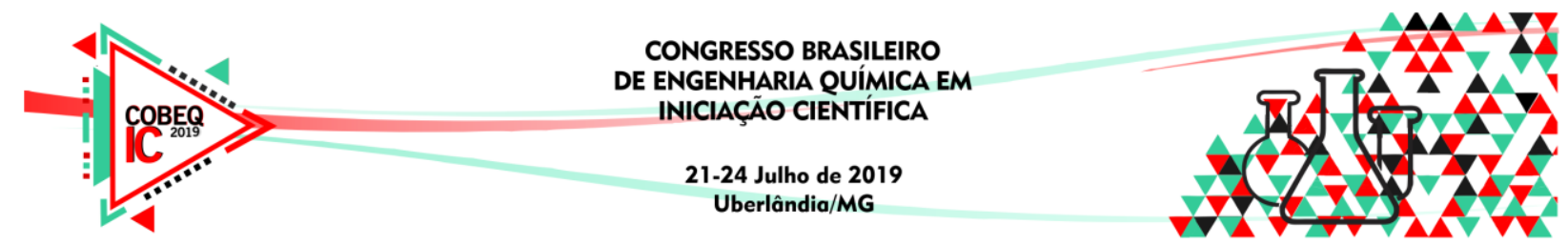

localizado no Rio de Janeiro, onde foram realizadas as análises de compostos fenólicos totais e a capacidade antioxidante pelo método ABTS.

\subsection{Métodos Analíticos}

Compostos fenólicos totais: A determinação de compostos fenólicos totais (CFT) foi realizada de acordo com a metodologia descrita por Singleton \& Rossi (1965), utilizando o reagente Folin Ciocalteau. Primeiramente os compostos fenólicos foram extraídos em acetona $70 \%$ por 30 minutos sob agitação constante. Em seguida os extratos foram diluídos (1:10) com água destilada e utilizados na quantificação. Após a reação, os extratos foram lidos a 760 $\mathrm{nm}$ em um espectrofotômetro (METASH). Os resultados foram expressos em $\mathrm{mg}$ de ácido gálico em 100 gramas de amostras, pela elaboração de uma curva padrão de ácido gálico.

Capacidade antioxidante: A capacidade antioxidante (CA) foi realizada pelo método de redução do radical $\mathrm{ABTS}+\bullet$, onde este é convertido à forma oxidada segundo $\operatorname{Re}$ et al. (1999). Para tal, as amostras foram extraídas com $10 \mathrm{~mL}$ de metanol $50 \%$ por 1 hora, sendo o sobrenadante separado após a centrifugação. Ao precipitado foram adicionados $10 \mathrm{~mL}$ de acetona $70 \%$ e procedeu-se a extração conforme citada acima. Os sobrenadantes foram combinados em um balão de $25 \mathrm{~mL}$, sendo o volume completado com água destilada. Assim, uma alíquota de $30 \mu \mathrm{L}$ de extrato das amostras foi reagida com $3 \mathrm{~mL}$ de ABTS+• por 6 minutos. A absorbância foi medida a $734 \mathrm{~nm}$. Os resultados foram expressos em $\mu$ mol de Trolox por grama de resíduo da fruta.

\subsection{Análise dos Dados}

Em ambas as determinações, os ensaios foram realizados em triplicata, sendo os mesmos expressos em média e desvio padrão. Os resultados foram submetidos à análise de variância (ANOVA), considerando o teste de Tukey para verificar a existência de diferença significativa entre eles num intervalo de confiança de $95 \%$.

\section{RESULTADOS E DISCUSSÃO}

O conteúdo de compostos fenólicos totais dos resíduos é mostrado na Tabela 1. De acordo com os dados, observa-se que o resíduo da laranja apresentou maior teor destes metabólitos secundários quando comparado ao resíduo de mamão $(\mathrm{p}<0,05)$. Essa diferença pode ser atribuída à matriz.

Segundo Barrales et al. (2018), a casca de laranja, na melhor condição de extração, apresentou conteúdo de compostos fenólicos superior a $1500 \mathrm{mg} / 100 \mathrm{~g}$ de amostra, sendo, portanto, muito superior aos dados reportados por Reis et al. (2015) para o teor dos mesmos compostos em mamões de diferentes variedades, os quais variaram de 20 a $78 \mathrm{mg} / 100 \mathrm{~g}$ de amostras. Além disso, de acordo com Soares et al. (2008), a diferença observada nos conteúdos de compostos fenólicos dos resíduos avaliados, pode estar associada também a fatores como a forma de cultivo, clima e estádio de maturação das frutas.

Os resultados para a capacidade antioxidante dos resíduos, mensurados pelo método ABTS, são apresentados na Tabela 1. A farinha de resíduo de laranja apresentou a maior 


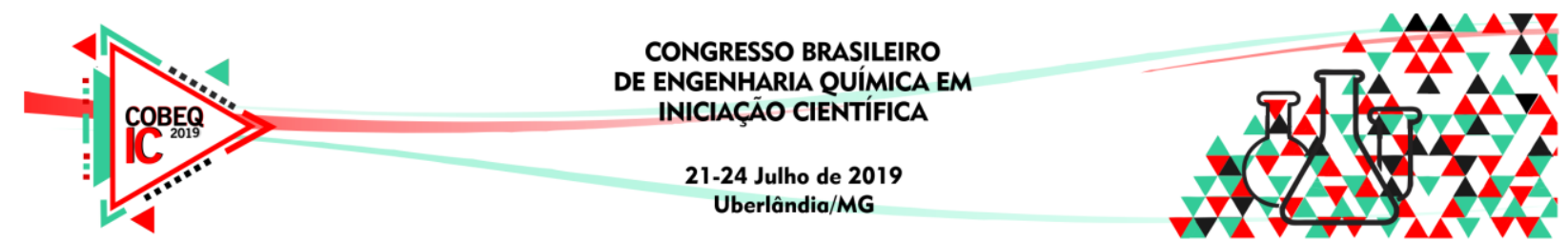

capacidade antioxidante, com valor médio de 7,90 $\mu$ mol Trolox/g de amostra, superando, novamente, a farinha de resíduo de mamão $(\mathrm{p}<0,05)$. Os resultados obtidos também corroboraram os dados da literatura, os quais destacam a existência de correlação positiva entre o teor de compostos fenólicos totais e a capacidade antioxidante. Ou seja, o resíduo que apresentou maior teor de compostos fenólicos totais foi também aquele que apresentou a maior capacidade antioxidante (Jacobo-Velázquez e Cisneros-Zevallos, 2009).

Tabela 1 - Teor de compostos fenólicos totais e capacidade antioxidante (CA) das farinhas de resíduos de laranja e de mamão

\begin{tabular}{|c|c|c|c|c|}
\hline Amostras & $\begin{array}{c}\text { Fenólicos Totais } \\
(\mathrm{mg} \text { ac. gal/100g })\end{array}$ & Desvio Padrão & $\begin{array}{c}\text { CA } \\
(\mu \mathrm{mol} \text { Trolox } / \mathrm{g})\end{array}$ & Desvio Padrão \\
\hline Farinha de Laranja & $154,45^{\mathrm{a}}$ & 9,74 & $7,90^{\mathrm{a}}$ & 0,41 \\
\hline Farinha de Mamão & $36,05^{\mathrm{b}}$ & 0,53 & $0,52^{\mathrm{b}}$ & 0,07 \\
\hline
\end{tabular}

Letras diferentes na mesma coluna indicam diferença estatística entre as médias $(\mathrm{p}<0,05)$.

\section{CONCLUSÃO}

Os resultados obtidos mostraram que as farinha de resíduo de laranja e de mamão podem ser considerados uma alternativa para a obtenção de compostos fenólicos, antioxidantes naturais, o que atende as demandas dos consumidores atuais, os quais buscam por produtos mais saudáveis, uma vez que os compostos extraídos podem ser aplicados como substitutos parciais ou integrais de seus similares sintéticos como o BHA e BHT. Além disso, o uso das farinhas como complemento alimentar deve ser ressaltado, devido ao seu potencial bioativo.

\section{REFERÊNCIAS}

BARRALES, F. M.; SILVEIRA, P.; BARBOSA, P. P. M.; RUVIARO, A. R.; PAULINO, B. N.; PASTORE, G. M.; MACEDO, G. A.; MARTINEZ, J. Recovery of phenolic compounds from citru by-products using pressurized liquids - Na applocation to Orange peel. Food and Bioproducts Processing, São Paulo, 112, 9-21, 2018.

COUTO, M. A. L.; CANNIATTI-BRAZACA, S. G. Quantificação de vitamina C e capacidade antioxidante de variedades cítricas. Ciência e Tecnologia de Alimentos, Campinas, v. 30, n. 1, p. 15-19, mai. 2010.

CRISTO, T. W. D.; RODRIGUES, B, M.; SANTOS, C, J, C.; SANTOS, E, F.; NOVELlO, D. Barra de cereais com adição de farinha de casca de chuchu: caracterização físico- 


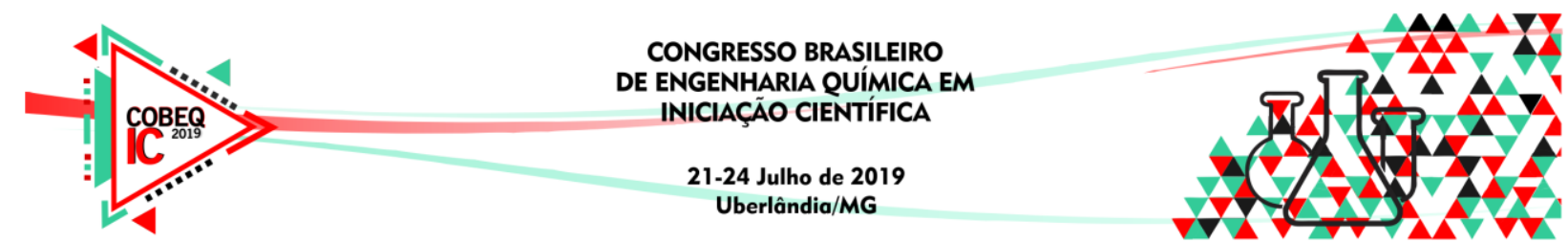

química e sensorial entre crianças. Ciências Biológicas e da Saúde, Londrina, v. 36, n. 2, p. 85-96, jul/dez. 2015.

JACOBO-VELÁZQUEZ, D. A.; CISNEROS-ZEVALLOS, L. Correlations of Antioxidant Activity against Phenolic Content Revisited: A New Approach in Data Analysis for Food and Medicinal Plants. Journal of food Science, v. 74, n. 9, 2009.

MELO, E. A.; MACIEL, M, I, S.; LIMA, V, L, A, G.; NASCIMENTO, R, J. Capacidade antioxidante de frutas. Revista Brasileira de Ciências Farmacêuticas, São Paulo, v. 44, n. 2, p. 193-201, abr./jun. 2008.

RE, R.; PROTEGGENTE, A.; PANNALA, A.; YANG, M.; RICE-EVANS, C. Antioxidant activity applying an improved ABTS radical cation decolorization assay. Free Radical Biology and Medicine, 26, 1231-1237, may. 1999.

REIS, R. C.; VIANA, E. S.; JESUS, L. F. L.; LIMA, L. F.; NEVES, T. T.; CONCEIÇÃO, E. A. Compostos bioativos e atividade antioxidante de variedades melhoradas de mamão. Ciência Rural, Santa Maria, v. 45, n. 11, p. 2076-2081, nov. 2015.

ROESLER, R.; MALTA, L, G.; CARRASCO, L, C.; HOLANDA, R, B.; SOUSA, C, A, S.; PASTORE, G, M. Atividade antioxidante de frutas do cerrado. Ciência e Tecnologia de Alimentos, Campinas, v. 27, n. 1, p. 53-60, jan/mar. 2007.

ROCHA, W. S.; LOPES, R, M.; SILVA, D, B.; VIEIRA, R, F.; SILVA, J, P.; AGOSTINICOSTA, T, S. Compostos fenólicos totais e taninos condensados em frutas nativas do cerrado. Revista Brasileira de Fruticultura, Jaboticabal - SP, v. 33, n. 4, p. 1215-1221, dez. 2011.

SINGLETON, V. L., ROSSI, J. A. Colorimetry of total phenolics with phosphomolybdicphosphotungstic acid reagents. Am. J. Enol. Vitic, 16, 144-158, jan. 1965.

SOARES, M.; WELTER, L.; KUSHOSKI, E, M.; GONZAGA, L.; FETT, R. Compostos fenólicos e atividade antioxidante da casca de uvas niágara e isabel. Revista Brasileira de Fruticultura, Jaboticabal, v. 30, n. 1, p. 059-064, 2008. 